NBER WORKING PAPER SERIES

OPTIMAL DEBT MANAGEMENT

Robert J. Barro

Working Paper 5327

\author{
NATIONAL BUREAU OF ECONOMIC RESEARCH \\ 1050 Massachusetts Avenue \\ Cambridge, MA 02138 \\ October 1995
}

I was motivated to consider this topic by questions that arose during my visit as HoublonNorman Fellow at the Bank of England in 1994-95. I am grateful to Mervyn King and the research staff of the Bank for their input during my visit. I have benefited from comments by John Campbell and Greg Mankiw. This research has been supported by the National Science Foundation. This paper is part of NBER's research programs in Economic Fluctuations, Growth, and Public Economics. Any opinions expressed are those of the author and not those of the National Bureau of Economic Research.

(C) 1995 by Robert J. Barro. All rights reserved. Short sections of text, not to exceed two paragraphs, may be quoted without explicit permission provided that full credit, including $\odot$ notice, is given to the source. 


\title{
OPTIMAL DEBT MANAGEMENT
}

\begin{abstract}
Optimal debt management can be thought of in three stages. First, if taxes are lump sum and the other conditions for Ricardian equivalence hold, then the division of government financing between debt and taxes is irrelevant, and the whole level of public debt is indeterminate from an optimal-tax standpoint. Second, if taxes are distorting, then the timing of taxes will generally matter; for example, it may be desirable to smooth tax rates over time. This consideration makes determinate the levels of debt at various dates, but does not pin down the composition of the debt, say by maturity. Finally, if there is uncertainty about real interest rates, levels of public outlay, GDP, and so on, then the relation of tax rates to states of nature becomes important. In some cases, optimal taxation dictates the smoothing of tax rates over states of nature, and this element may pin down the composition of the debt. For example, the maturity structure can be designed to insulate the government's financing costs from shifts in real interest rates.

This paper studies dynamic optimal taxation in an equilibrium model that yields a form of tax smoothing as a basis for debt management. The main analysis uses a tractable form of the one-sector stochastic growth model. The type of taxation that yields the clearest results on tax smoothing is a proportional levy on consumption. In a simple benchmark case, optimal debt management entails the issue of indexed consols. More generally, payouts on debt would also be contingent on aggregate consumption and the level of government spending.
\end{abstract}

Robert J. Barro

Department of Economics

Littauer Center 120

Harvard University

Cambridge, MA 02138

and NBER 
In standard macroeconomics, fiscal policy consists of choices about expenditures, taxes, and debt issue. The kinds of public spending may be distinguished in terms of their interaction with private decisions; for example, some public activities would influence private production and some would interact with the choices of consumption and leisure. The taxes may also be differentiated by type-levies may fall on labor income, capital income, consumption, bodies, and so on.

A fiscal authority also chooses its type of debt obligations. These choices include the maturity structure of the debt, whether to issue nominal bonds or bonds indexed to the price level, and whether the debt payments should be contingent on other variables (GDP, foreign exchange rates, war or peace, and so on). These kinds of decisions are less familiar as a part of macroeconomics, although some aspects have been studied by Lucas and Stokey (1983); Persson and Svensson (1984); Bohn (1988, 1990); Calvo and Guidotti (1990); Alesina, Prati, and Tabellini (1990); Giavazzi and Pagano (1990); Chari, Christiano, and Kehoe (1994); and Missale and Blanchard (1994).

Optimal debt management can be thought of in three stages. First, if taxes are lump sum and the other conditions for Ricardian equivalence hold, then the division of government financing between debt and taxes is irrelevant. Thus, the whole level of public debt will be indeterminate from an optimal-tax standpoint.

Second, if taxes are distorting - for example, because the amount paid depends on an individual's labor income or consumption-then the timing of taxes will generally matter, as in Barro (1979). This consideration tends to motivate smoothing of tax rates over time and thereby makes determinate the levels of debt at various dates. However, this element does not pin down the composition of debt, say by maturity.

Finally, if there is uncertainty about real interest rates, levels of public outlay, and the tax base (say aggregate consumption or GDP), then the kinds of debt that the government issues will matter. In particular, the government may want to smooth tax 
rates over states of nature, and this consideration may dictate an appropriate structure of the public debt. As an example, the maturity structure of the debt can be designed to insulate the government's financing costs from shifts in real interest rates.

The strategy in this paper is to study dynamic optimal taxation in a tractable equilibrium model that yields a form of tax smoothing as a basis for debt management. One essential element in the model is that the allowable form of taxation be at least potentially distorting. Second, some elements of uncertainty are crucial. Third, the basic idea of tax smoothing is that it involves taxes and allocations now versus taxes and allocations later. This tradeoff arises naturally if the model includes productive investment and individual choices between consumption and saving. A familiar framework that captures this tradeoff is the stochastic, one-sector growth model with no labor-leisure choice. The present analysis focuses on a tractable version of this model in which the technology is linear in capital, so that diminishing returns do not apply. Finally, the type of taxation that yields the clearest results on tax-rate smoothing is a proportional levy on consumption.

The main analysis assumes that policymakers can make effective commitments about the form of future actions. Hence, unlike Lucas and Stokey (1983) and Persson and Svensson (1984), the debt structure is not set to ensure that policies are time consistent. However, time consistency is addressed in a later section.

The primary focus is on a non-monetary economy, so that the choice of public debt structure abstracts from interactions with inflation and monetary policy. Hence, unlike Calvo and Guidotti (1990) and Missale and Blanchard (1994), the choice of debt maturity does not interact with the determination of inflation in an environment of nominal bonds and imperfect policy commitment. Nominal debt and inflation are, however, considered in a later section. 
A reading of the literature gives the impression that public debt management-in particular, the determination of the maturity structure of the debt-is an uninteresting problem in a purely real economy in which the government already has an effective commitment technology. This paper suggests that this idea is incorrect and that optimal debt management emerges naturally from a simple analysis of tax-rate smoothing. Probably it would have been better if the literature had worked out this elementary perspective on optimal debt management first and then gone on later to consider interesting, but complicated, extensions to time-consistency issues and the interactions between fiscal and monetary policies.

\section{The Basic Framework}

The analysis begins with a stochastic growth model that has no public sector. Goods are produced by means of a linear (AK) technology,

$$
Y_{t}=A v_{t} K_{t-1}
$$

where $Y_{t}$ is output (GDP) for period $t, A>0$ is a constant, $v_{t}$ is a positive random variable, and $K_{t-1}$ is the stock of capital at the end of period $t-1$. The constant returns assumption is most realistic if capital is construed broadly to encompass human and non-human components. Claims to the human parts of this capital may not be tradeable on markets.

Gross output can be used for consumption, $C_{t}$, net investment, $K_{t}-K_{t-1}$, and a possibly stochastic amount of depreciation, $\delta_{t} \mathrm{~K}_{\mathrm{t}-1}$, where $\delta_{\mathrm{t}}<1$ is a random variable. Depreciation can be interpreted as any change that affects the value and usefulness of existing capital; hence, $\delta_{t}<0$ is possible. The capital stock at the end of period $t$ is given by 


$$
K_{t}=\left(1+A v_{t}-\delta_{t}\right) \cdot K_{t-1}-C_{t}
$$

The distribution of $\left(v_{t}, \delta_{t}\right)$ is assumed to be first-order Markov; that is, it depends on $\left(v_{t-1}, \delta_{t-1}\right)$ and some parameters. However, the main results would not change if the disturbances were subject to a richer pattern of serial dependence.

In practice, $Y_{t}$ and $C_{t}$ would be observable in period $t$, at least if problems in measuring consumption are ignored. However, $K_{t}$ and $\delta_{t} K_{t-1}$ would typically be unobservable, at least to econometricians. If an initial (benchmark) value of the capital stock were known, then the entire history of $v_{t}$ and $\delta_{t}$-and, hence, of $K_{t} \longrightarrow$ could be inferred from the observed values of $Y_{t}$ and $C_{t}$. If no benchmark stock were known, then the realizations of $v_{t}$ and $\delta_{t}$ could be estimated based on some distributional assumptions. In any event, the assumption here is that $v_{t}, \delta_{t}$, and $K_{t}$ are observable at date $\mathbf{t}$.

The representative household seeks at an initial time 1 to maximize the expected value of utility over an infinite horizon, where the utility function takes a standard, time-separable form with constant relative risk aversion:

(3) maximize $\mathrm{E}_{1}\left[\frac{\mathrm{C}_{1}^{1-\theta}-1}{1-\theta}+\left[\frac{1}{1+\rho}\right] \cdot\left[\frac{\mathrm{C}_{2}^{1-\theta}-1}{1-\theta}\right]+\left[\frac{1}{1+\rho}\right]^{2} \cdot\left[\frac{\mathrm{C}_{3}^{1-\theta}-1}{1-\theta}\right]+\ldots\right]$, where $\rho>0$ is the constant rate of time preference and $\theta>0$ indicates the degree of risk aversion. A higher $\theta$ implies a reduced willingness to substitute intertemporally.

The maximization of expected utility in equation (3), subject to the budget constraint in equation (2), leads to a familiar set of first-order conditions:

$$
(1+\rho) \cdot\left(\mathrm{C}_{\mathrm{t}}\right)^{-\theta}=\mathrm{E}_{\mathrm{t}}\left[\left(1+\mathrm{Av}_{\mathrm{t}+1}-\delta_{\mathrm{t}+1}\right) \cdot\left(\mathrm{C}_{\mathrm{t}+1}\right)^{-\theta}\right]
$$


for $t=1, \ldots$ The expression on the right-hand side involves the stochastic rate of return on capital between periods $t$ and $t+1$ :

$$
r_{t k} \equiv A v_{t+1}-\delta_{t+1}
$$

Because of stochastic depreciation, the innovations to $r_{t k}$ are not perfectly correlated with those to next period's GDP ( $Y_{t+1}$ from equation [1]).

Since the distribution of $\left(v_{t}, \delta_{t}\right)$ is first-order Markov, equation (2) suggests that $\mathrm{C}_{\mathrm{t}}$ would be some fraction of $\left(1+A v_{t}-\delta_{t}\right) \cdot \mathrm{K}_{\mathrm{t}-1}$-the total resources available to the representative household in period $\mathrm{t}$ - where the fraction may depend on the realizations of $v_{t}$ and $\delta_{t}$ :

$$
C_{t}=\phi\left(v_{t}, \delta_{t}\right) \cdot\left(1+A v_{t}-\delta_{t}\right) \cdot K_{t-1}
$$

If the conjectured form is correct, then $\phi(\cdot)$ must be such as to satisfy the first-order condition given in equation (4) for all realization of $\left(v_{t}, \delta_{t}\right)$.

Substitution from equation (6) into equation (4) leads to an expression for the first-order condition:

$$
(1+\rho) \cdot\left[\frac{\left[1-\phi\left(v_{t}, \delta_{t}\right)\right]}{\phi\left(v_{t}, \delta_{t}\right)}\right]^{\theta}=E_{t}\left[\frac{\left(1+A v_{t+1}{ }^{-} \delta_{t+1}\right)^{1-\theta}}{\left[\left(v_{t+1}, \delta_{t+1}\right)\right]^{\theta}}\right]
$$

If $A v_{t+1}-\delta_{t+1}$ is distributed i.i.d. - in particular, independently of $\left(v_{t}, \delta_{t}\right)$-then equation (7) implies that $\phi(\cdot)$ is a constant, determined as

$$
\phi(\cdot)=1-\left[\frac{1}{(1+\rho)} \cdot \mathrm{E}_{\mathrm{t}}\left(1+\mathrm{A} \mathrm{v}_{\mathrm{t}+1}-\delta_{\mathrm{t}+1}\right)^{1-\theta}\right]^{1 / \theta} .
$$


If $A v_{t+1}-\delta_{t+1}$ exhibits serial dependence, then the presence of the term $\left(1+A v_{t+1}-\delta_{t+1}\right)^{1-\theta}$ on the right-hand side of equation (7) implies that $\phi(\cdot)$ would generally have to depend on its arguments in a complicated way to satisfy the first-order condition for all realizations of $v_{t}$ and $\delta_{t}$. However, for $\theta=1(\log u$ tility), the term $\left(1+A v_{t+1}-\delta_{t+1}\right)^{1-\theta}$ vanishes, and equation ( 7$)$ is satisfied for all values of $v_{t}$ and $\delta_{t}$ for a constant $\phi(\cdot)$, given by 1

$$
\phi(\cdot)=\rho /(1+\rho)
$$

Thus, the solution to the model is simple in two cases: i.i.d. shocks and log utility. The subsequent discussion assumes log utility in order to focus on manageable closed forms while allowing for serial dependence of the random variables. However, the main results for public finance do not depend on log utility (or on the closed-form solutions that derive from this assumption).

The result in equation (9) implies that consumption and capital stock are determined as

$$
\begin{aligned}
& C_{t}=\left(\frac{\rho}{1+\rho}\right) \cdot\left(1+A v_{t}-\delta_{t}\right) \cdot K_{t-1}, \\
& K_{t}=\left(\frac{1}{1+\rho}\right) \cdot\left(1+A v_{t}-\delta_{t}\right) \cdot K_{t-1},
\end{aligned}
$$

1Stokey and Lucas (1989, Ch. 2) provide parallel results for a Cobb-Douglas technology, which specifies diminishing returns for output with respect to capital. Simple closed-form results then apply with $100 \%$ depreciation $\left(\delta_{t}=1\right)$ or if depreciation takes a Cobb-Douglas form. However, $100 \%$ depreciation is obviously unappealing, and Cobb-Douglas depreciation means-counter-intuitively - that the rate of depreciation declines with the quantity of capital. If the technology is linear, then linear depreciation is consistent with a simple closed-form solution. 
for $t=1, \ldots$ This solution is valid if the constraint of nonnegative gross investment, $K_{t} \geq\left(1-\delta_{t}\right) \cdot K_{t-1}$ for $t=1, \ldots$, is never binding, a condition that corresponds to $A v_{t} \geq \rho \cdot\left(1-\delta_{t}\right)$ for all realizations of $v_{t}$ and $\delta_{t}$. Alternatively, the solution is satisfactory if investment is reversible so that the existing capital stock can be consumed if desired.

Equations (11), (10), and (1) imply that the growth of capital stock, consumption, and GDP are described by

$$
\begin{gathered}
\mathrm{K}_{\mathrm{t}+1} / \mathrm{K}_{\mathrm{t}}=\mathrm{C}_{\mathrm{t}+1} / \mathrm{C}_{\mathrm{t}}=\left(\frac{1}{1+\rho}\right) \cdot\left(1+A v_{t+1}-\delta_{t+1}\right)=\left(\frac{1}{1+\rho}\right) \cdot\left(1+\mathrm{r}_{\mathrm{tk}}\right) \\
\mathrm{Y}_{\mathrm{t}+1} / \mathrm{Y}_{\mathrm{t}}=\left(\frac{1}{1+\rho}\right) \cdot\left(1+A v_{t}-\delta_{t}\right) \cdot\left(\mathrm{v}_{\mathrm{t}+1} / \mathrm{v}_{\mathrm{t}}\right)
\end{gathered}
$$

where $r_{t k}$ is the rate of return on capital from equation (5). Note from equation (12) that $\rho>0$ implies that the mean of $r_{\text {tk }}$ exceeds the mean growth rate of the capital stock, a property that corresponds to the usual transversality condition in the deterministic version of the neoclassical growth model (see Barro and Sala-i-Martin [1995, Chs. 2 and 4]). If $v_{t+1} / v_{t}$ had mean unity (no technological progress) and was distributed independently of $A v_{t}-\delta_{t}$, then the long-run average growth rate of GDP from equation (13) would equal the long-run average growth rates of capital and consumption from equation (12).

Equation (12) implies that consumption growth and the rate of return on capital are perfectly correlated. ${ }^{2}$ This result is problematic if $\mathbf{r}_{\mathbf{t k}}$ is identified with the real rate of return on the stock market. For example, for U.S. quarterly data from 1948 to 1994, the correlation of total real stock returns (growth rate of the S\&P 500 stock-price index less the rate of CPI inflation plus the S\&P 500 dividend yield) with the growth rate of seasonally-adjusted real consumer expenditure is positive but only 0.3 . Similar results

2This type of result is stressed in Campbell and Cochrane (1994, section 8). 
apply for other measures of aggregate consumption, at other data frequencies, and in other countries; see Campbell (1995, Table 5). Mankiw and Zeldes (1991) show, however, that the correlation between stock returns and consumption growth at the household level is much higher for those that own stocks than for those who do not.

One possible explanation for the low-correlation puzzle is that the real return on a broad measure of capital is not well proxied by the real return on stocks (which are highly levered and do not consider returns on human capital or on many components of physical capital). Consumption growth may actually be highly correlated with the real return on broad capital, but this return-as well as consumption itself-cannot be measured very well.

As is well known-for example, from Breeden (1979) and Grossman and Shiller (1982) - this type of model can be used to price any kind of internally generated asset. If $r_{t}$ is the real rate of return on any asset between periods $t$ and $t+1$, then consumer optimization implies first-order conditions of the form of equation (4):3

$$
(1+\rho) \cdot\left(\mathrm{C}_{\mathrm{t}}\right)^{-\theta}=\mathrm{E}_{\mathrm{t}}\left[\left(1+\mathrm{r}_{\mathrm{t}}\right) \cdot\left(\mathrm{C}_{\mathrm{t}+1}\right)^{-\theta}\right] .
$$

Hence, the right-hand side of equation (14) must be the same for all asset returns, $r_{t}$.

If $\theta=1$, then the one-period riskless real rate of return, $\mathbf{r}_{\mathrm{t} 1}$, is given from equations (14) and (12) by

$$
\frac{1}{1+r_{t 1}}=\left(\frac{1}{\Gamma+\rho}\right) \cdot E_{t}\left(C_{t} / C_{t+1}\right)=E_{t}\left(\frac{1}{1+r_{t k}}\right)
$$

${ }^{3}$ This result holds if individuals can hold positive or negative amounts of any asset, although the representative household must hold a zero quantity of each internally generated asset in equilibrium. Negative holdings must be subject to restrictions that rule out Ponzi games for debt. 
If $\mathbf{r}_{\mathbf{t k}}$ is small relative to 1 (with high probability), then a Taylor-series approximation using linear and squared terms leads to

$$
r_{t 1} \approx E_{t} r_{t k}-\operatorname{VAR}_{t}\left(r_{t k}\right)
$$

where $\operatorname{VAR}_{t}\left(r_{t k}\right)$ is the variance of the return on capital conditional on information available at the start of period $t$. Equation (16) implies that the "equity premium," $E_{t} r_{t k}-r_{t 1}$, is approximately equal to the variance of the equity return.

This result accords reasonably well with data if $r_{t k}$ is identified with the real rate of return on stocks and $r_{t 1}$ with the real rate of return on a short-term government instrument, such as a 3-month treasury bill. Data for several OECD countries in the post-World War II period are given in Campbell (1995, Table 2). Probably most interesting are the long-term results: for the United States from 1890 to 1992, the equity premium is $4.4 \%\left(\mathrm{r}_{\mathrm{tk}}=6.4 \%, \mathrm{r}_{\mathrm{t} 1}=2.0 \%\right)$, and $\sigma^{2}$ is $3.5 \%$. For the United Kingdom from 1919 to 1993 , the premium is $6.3 \%\left(r_{t k}=7.5 \%, r_{t 1}=1.2 \%\right)$, and $\sigma^{2}$ is $5.2 \%$. For Sweden from 1919 to 1993 , the premium is $3.9 \%\left(\mathrm{r}_{\mathrm{tk}}=5.8 \%, \mathrm{r}_{\mathrm{t} 1}=1.9 \%\right)$, and $\sigma^{2}$ is $3.7 \% .4$ These results do not, of course, eliminate the problem posed by the low correlation between stock-market returns and consumption growth. Rather, the point is that the various finance puzzles may be expressible as a single puzzle, rather than many.

The presence of $\operatorname{VAR}_{t}\left(r_{t k}\right)$ in equation (16) may help to explain the observed lack of correlation between riskless rates of return (approximated, say, by real returns on U.S. Treasury bills) and consumption growth. In the model with log utility, an increase in $\operatorname{VAR}_{t}\left(r_{t k}\right)$ reduces $r_{t 1}$ but does not affect consumption growth; hence, the correlation

4These comparisons are reminiscent of those carried out on U.S. data by Friend and Blume (1975). 
between $r_{t 1}$ and the mean of consumption growth may be small. Moreover, if utility were not logarithmic, then it would be possible for an increase in $\operatorname{VAR}_{t}\left(r_{t k}\right)$ to raise the mean of consumption growth (by raising saving) while lowering $r_{t 1}$. Therefore, the correlation between $\mathbf{r}_{\mathbf{t} 1}$ and consumption growth need not be positive.

Equation (16) shows that $r_{t 1}<0$ is possible although quantitatively unlikely with plausible parameter values. However, $r_{t 1}$ is likely to be less than the expected growth rate of capital, consumption, and GDP, as determined from equations (12) and (13). In particular, a shortfall of the riskless real rate of return from the mean growth rate of the capital stock does not violate any transversality condition. ${ }^{5}$

The model can also be used to price longer duration riskless claims. Consider, for example, a two-period riskless real asset, where each unit issued in period $t$ is defined to pay off $\left(1+r_{t 2}\right) \cdot\left(1+r_{t 2}\right)$ units in period $t+2$. Equation (14) and Taylor-series approximations can be used to relate $r_{t 2}$ to $r_{t 1}$ and $E_{t} r_{t+1,1}$; that is, to derive the term premium. The result can be expressed as

$$
\frac{\left(1+r_{t 1}\right) \cdot E_{t}\left(1+r_{t+1,1}\right)}{\left(1+r_{t 2}\right) \cdot\left(1+r_{t 2}\right)} \approx 1+\operatorname{CoV}_{t}\left(r_{t k}, r_{t+1, k}\right)
$$

where $\mathrm{COV}_{t}$ is the covariance between $r_{t k}$ and $r_{t+1, k}$ conditional on information available in period $t$. Thus, if returns on capital co-vary positively over time, then a sequence of two one-period returns includes a risk premium relative to the two-period risk-free return. ${ }^{\circ}$ Put alternatively, if the returns on capital exhibit positive serial

5This type of result on riskless real rates of return is highlighted in Abel, et al (1989, pp. 13-14).

${ }^{6} \mathrm{~A}$ high value of $\mathrm{r}_{t k}$ goes along with a high value of $\mathrm{C}_{t+1}$ and-with positive serial correlation in returns - $a$ high value of $E_{t+1} r_{t+1, k}$. The high value of $E_{t+1} r_{t+1, k}$ depresses the price in period $t+1$ of a 2-period riskless claim that was issued at time $t$. Therefore, the 2 -period riskless asset pays off poorly after 1 period in good times (when 
correlation, then the real term structure would usually be downward sloping.

If $r_{t k}$ is again identified with real stock returns, then the covariances between $r_{t k}$ and its own lags are small; see Campbell (1995, Table 2). Therefore, the term structure for riskless real returns would be roughly flat on average. This result accords with data on U.K. indexed bonds for maturities of one year or more. (See Breedon [1995] and Bank of England [1995] for discussion.) The empirical observation that the term structure is usually upward sloping applies to nominal bonds, and this pattern seems to derive from the behavior of inflation rates. Nominal debt is discussed in a later section.

\section{Public Finance}

Assume now that the government finances an exogenous amount of purchases of goods and services in period $t, G_{t}$, with (real) taxes, $T_{t}$, and net (real) issues of public debt (gross issues less payments on and purchases of old debt). As already mentioned, the basic notion will be that the government seeks to manage its debt to smooth tax rates over time and states of nature, an idea that derives from Pigou (1928), Barro (1979), Lucas and Stokey (1983), Bohn (1990), and Judd (1991).

The timing of tax rates typically matters if taxes are distorting. If taxes are applied to consumption or labor income, then smoothing tends to be desirable because distortions typically increase more than proportionately with the rate of tax levied in a particular time period or state of nature. However, a tax on capital income amounts to the application of a higher tax rate on future consumption than on present consumption. Hence, the smoothing of consumption tax rates over time would correspond to a secularly declining pattern of tax rates on capital income, as prescribed in Judd (1985)

$\mathrm{C}_{\mathrm{t}+1}$ is high) and well in bad times. This desirable risk characteristic lowers the equilibrium value of $r_{t 2}$ in relation to $r_{t 1}$ and $E_{t} r_{t+1,1}$. 
and Chamley (1986). The analysis would therefore not be expected to predict smoothing over time of tax rates on capital income.

\section{A. Consumption Taxes}

The clearest results on debt as a mechanism for tax smoothing emerge with proportional consumption taxes; that is, if taxes for period $t$ are constrained to take the form $T_{t}=\tau_{t} C_{t}$. In this case, the government's budget constraint for period $t$ is

$$
\tau_{t} C_{t}=G_{t}-\text { net debt issue, }
$$

where the details of debt issue are considered later.

The consumption tax modifies the representative household's budget constraint from equation (2) to

$$
K_{t}=\left(1+A v_{t}-\delta_{t}\right) \cdot K_{t-1}-\left(1+\tau_{t}\right) \cdot C_{t}-\text { net debt acquisition, }
$$

where the last term is the household's accumulation of government obligations (purchases less payments on and sales of previous holdings) for period t. The government's purchases, $G_{t}$, are assumed not to affect productivity, represented by the parameter A, or the security of property rights (see Barro and Sala-i-Martin [1995, Ch. 4]).

Each household now maximizes expected utility in equation (3) while treating the path of tax rates, $\tau_{t}$, as exogenous in the budget constraint shown in equation (19). The government's purchases, $G_{t}$, are assumed not to influence the marginal utilities of consumption at various dates; that is, $G_{t}$ either does not affect utility or else enters in a separable way from the $C_{t}$ 's. 
The consumption tax changes the household's first-order condition from equation (4) to

(20) $\quad(1+\rho) \cdot\left(\mathrm{C}_{\mathrm{t}}\right)^{-\theta} /\left(1+\tau_{\mathrm{t}}\right)=\mathrm{E}_{\mathrm{t}}\left[\left(1+\mathrm{A} \mathrm{v}_{\mathrm{t}+1}-\delta_{\mathrm{t}+1}\right) \cdot\left(\mathrm{C}_{\mathrm{t}+1}\right)^{-\theta} /\left(1+\tau_{\mathrm{t}+1}\right)\right]$.

Thus, anticipated variations in tax rates over time can induce changes in the timing of consumption.

In equilibrium, the households' net debt acquisition for each period in equation (19) equals the government's net issue in equation (18). Therefore, the budget constraint for period $t$ becomes

$$
K_{t}=\left(1+A v_{t}-\delta_{t}\right) \cdot K_{t-1}-C_{t}-G_{t}
$$

Equation (21) says that the resource cost of government is the outlay on purchases, $G_{t}$, and does not involve the split of financing between taxes and net debt issue. However, the financing choice will matter for the equilibrium if it affects households' choices; specifically, if it changes the allocation of income between consumption and saving (or, in a more general model, the choice between consumption and leisure).

A closed-form solution for $C_{t}$ and the other variables cannot be found for general processes for $G_{t}$ and $\tau_{t}$ (which have to be restricted to be consistent with the government's budget constraint). However, it is easy to characterize the optimal behavior of consumption tax rates by considering the related social planner's problem.

The social planner seeks to maximize the expected utility of the representative household from equation (3), subject to the economy's resource constraint in equation (21). (The path of $G_{t}$ is still taken as exogenous, although the $G_{t}$ could instead be entered in a separable way into the utility function and then chosen in an 
optimizing manner.) Thus, equation (21) applies in the same way for the social plan and the decentralized equilibrium.

The difference for the social planner is that the first-order condition can readily be shown to be equation (4); that is, the version of equation (20) in which taxes are lump sum, so that $\tau_{t+1}=\tau_{t}=0$ for $t \geq 1$. Notice, however, that the overall level of the tax rate does not matter in equation (20). ${ }^{7}$ The first-order condition in the decentralized case will match the social-planner's condition for any level of tax rates as long as perfect tax smoothing applies; that is, if $\tau_{t+1}=\tau_{t}$ for all $t \geq 1.8$ Furthermore, since the resource constraints are the same in the two cases, the matching of the first-order conditions implies that the equilibria will be the same. It follows that perfect tax-rate smoothing generates the social optimum within the decentralized context. Thus, from the perspective of the government's budget constraint in equation (18), the optimal policy is, if possible, to choose a path of net debt issue that stabilizes the consumption tax rate, $\tau_{t}$, for $t \geq 1$. The next section considers the form and evolution of public debt that is consistent with this tax-rate stabilization.

\section{B. Characterizing the Optimal Behavior of Public Debt}

Suppose, to begin, that the government issues only indexed bonds, which guarantee a real payment at various future dates. The subsequent sections allow for debt with payouts that are contingent on the state of the economy.

7This result holds with a consumption tax in the absence of a labor-leisure choice. The conclusions on tax-rate smoothing tend to hold as an approximation even if a labor-leisure choice is introduced. However, this choice cannot be readily considered within the present AK framework.

BThis result for consumption tax rates appears in a different model in Chari, Christiano, and Kehoe (1994, p. 649). Analogous results are in Judd (1991) (for labor taxes) and Bohn (1990) (for taxes on GDP). In these last two cases, the excess burden each period from taxation is assumed to be a quadratic function of the tax rate during the period. 
Let $B_{t j}$ be the quantity of debt outstanding at the end of period $t$ with a prescribed payout in period $t+j$. That is, for a discount indexed bond, $B_{t j}$ is the total real principal that the government is committed in period $t$ to pay at the maturity date, $t+j$. For securities with coupons, the amount $B_{t j}$ includes real coupons paid in period $t+j$ on all obligations plus the real principal paid on debt that matures in period $t+j$.

Let $P_{t j}$ be the market price in period $t$ for public debt that pays out one unit of goods (as principal or coupon) in period $t+j$. These prices are determined as above from the equilibrium rates of return on riskless debt of various maturities.

With this structure of debt obligations, the government's budget constraint for period $t$ can be expressed from equation (18) as

$$
\tau_{t} C_{t}=G_{t}+B_{t-1,1}+P_{t 1} \cdot\left(B_{t-1,2}-B_{t 1}\right)+P_{t 2} \cdot\left(B_{t-1,3}-B_{t 2}\right)+\ldots
$$

The first debt term on the right-hand side of equation (22) is the payout (coupons and principal), $B_{t-1,1}$, on debt that matures in period $t$. The other terms are the government's net purchases of debt with maturities in periods $t+1, t+2, \ldots$ The government is assumed to begin in the initial period, period 1, with an arbitrary structure of outstanding debt, $\mathrm{B}_{01}, \mathrm{~B}_{02}, \ldots$, which was determined in period 0 .

Suppose for the moment that $C_{t}=C$ and $G_{t}=G$ are constant over time, but that each of the bond prices, $P_{t j}$, for $t>1, j \geq 1$, may exhibit independent random variation because of unpredictable changes in riskless rates of return. From an empirical standpoint, the extent of volatility in these rates of return can be gauged from the U.K. experience with indexed bonds. From 1982 to 1995, the 2-year-ahead real forward rate (for the subsequent 6 months) ranged from around $2 \%$ to $5-1 / 2 \%$, whereas the rate 20 years ahead varied from about $2-1 / 2 \%$ to $4-1 / 2 \%$. 
In the underlying model, disturbances that cause changes in the $P_{t j}$ will typically also affect $C_{t}$. In particular, in the setting without a government sector, consumption growth and the rate of return on capital, $r_{t k}$, always move together (equation [12]). However, riskless rates of return-which matter for the pricing of the government's indexed bonds-can change for a given mean of $r_{t k}$ if shifts occur in the variance of $r_{t k}$ (equation [16]) or in the dynamic covariances of $r_{t k}$ (equation [17]). Changes in government purchases would also weaken the relation between rates of return and consumption growth. In any event, in practice, consumption growth is virtually unrelated to riskless rates of return.

If the $P_{t j}$ move randomly, then $\tau_{t}=\tau_{1}$ for all $t>1$ and for all realizations of the $P_{t j}$ can hold only if each term $\left(B_{t-1, j+1}-B_{t j}\right)$ is set to zero for $t>1$ in equation (22). That is, in period 1 , the government makes a permanent arrangement for a pattern of debt by buying or selling securities as necessary at the equilibrium prices. In subsequent periods, the government makes the sequence of committed payouts, $B_{1 j}$ for $j \geq 1$, but neither sells new bonds nor buys back old ones.

In the present context, the motivation for setting the terms $\left(B_{t-1, j+1}-B_{t j}\right)$ to zero in equation (22) is to avoid effects on future government budget constraints from random variations in the $P_{t j}$. At the same time, the setting of these terms to zero means that the government will have adopted a plan that makes future budget constraints invariant at the margin to subsequent changes in policies that would affect the $P_{t j}$ 's. This feature is the basis for time consistency in the debt strategy derived by Lucas and Stokey (1983) (and explained by Persson and Svensson [1984]) for a model without capital that contains taxes on labor income. However, the present model raises different questions about time consistency, as discussed in a later section.

Divide equation (22) by $C_{t}=C$ and define $g \equiv G / C$ to get, after setting the terms that involve the $P_{t j}$ for $t>1$ to zero, 


$$
\begin{gathered}
\tau_{2}=\mathrm{g}+\mathrm{B}_{11} / \mathrm{C} \\
\tau_{3}=\mathrm{g}+\mathrm{B}_{12} / \mathrm{C}, \ldots
\end{gathered}
$$

Hence, $\tau_{2}=\tau_{3}=\ldots$ requires equality for all of the $B_{1 j}$ for $j \geq 1$.

The level of the payout in each period, which equals $B_{11}$, is determined from the budget constraint for period 1 , given by equation (22), and the smoothing condition for period $1, \tau_{1}=\tau_{2}$. This condition can be written as

$$
\mathrm{B}_{11} \cdot\left(1+\mathrm{P}_{11}+\mathrm{P}_{12}+\ldots\right)=\mathrm{B}_{01}+\mathrm{P}_{11} \mathrm{~B}_{02}+\mathrm{P}_{12} \mathrm{~B}_{03}+\ldots
$$

The right-hand side of equation (24) is the total market value of the period 0 (initial) debt evaluated at the (equilibrium) market prices of period 1. Since the payouts in each future period are the same- $B_{11}=B_{12}=\ldots$ - the left-hand side of equation (24) is the market value of the debt outstanding at the end of period 1 plus a hypothetical payout in period 1 of the same size, $B_{11}$. Thus, if the initial debt were structured as consols, so that $\mathrm{B}_{01}=\mathrm{B}_{02}=\ldots$, then equation (24) implies $\mathrm{B}_{11}=\mathrm{B}_{01}=\mathrm{B}_{02}=\ldots$, so that no restructuring of the debt would be required.

In order to satisfy its budget constraint in each period, the government must raise the revenue, $\tau \mathrm{C}=\mathrm{G}+\mathrm{B}_{11}$. This policy is feasible in the model if $\mathrm{G}<\mathrm{Y}_{t}$ applies in all periods. That is, as long as its purchases are less than gross domestic product, the government can always raise the tax rate high enough to generate the receipts to pay its bills. (Note that $\tau<1$ may not hold.) With a labor-leisure choice or possibilities for $\operatorname{tax}$ evasion, the feasibility restriction would be more severe.

One way to look at the answer, in terms of pure discount bonds, is that the maturity structure has no holes: the government structures the debt in period 1 so that 
the real amounts to be paid in each future period (up to $t=\infty$ ) are the same. 9 However, because of the discounting on future real payouts, the current market value of the outstanding debt declines steadily with maturity.

From the standpoint of coupon bonds, the government should structure the debt in period 1 as indexed perpetuities (consols). These issues pay a uniform and perpetual stream of real coupons but have no principal payments. ${ }^{10}$

The prescription for consols may seem to entail a maturity structure for the public debt that is much longer than that observed in practice. However, when governments issue real bonds, the stated maturity -and, more pertinently, the average duration of the payouts - tend to be long. For example, when Britain was effectively on the gold standard in the eighteenth and nineteenth centuries, nominal obligations were essentially real. At this time, the public debt was mainly long term ("funded") and often took the form of consols." 11 The U.S. debt issued under the gold standard before World War I was also primarily long term; for example, most of the U.S. government bonds outstanding in 1916 had remaining maturities in excess of 20 years. ${ }^{12}$

More recently, the U.K. government has issued indexed coupon bonds with maturities as long as 38 years, which is nearly infinity. Other countries with recent issues of indexed bonds have also employed long maturities (see Bank of

PAlesina, Prati, and Tabellini (1990) and Giavazzi and Pagano (1990) argue on different grounds - in order to avoid confidence crises - that similar amounts of public debt should come due in each period.

${ }^{10}$ These results on the desirable maturity structure of the public debt differ from the suggestions of Friedman (1959, p. 63): "I can find no valid argument for the present policy of issuing a wide variety of securities ... The alternative suggestion follows ... Issue ... debt in two standard forms, one short-term ... the other moderately long-term. The short security might be a 90 -day bill ... The longer security might best be a consol-that is, a perpetuity ... A less extreme break would be to make it, let us say, an eight-or ten-year maturity. I do not myself believe that the precise maturity of the debt outstanding is of great significance."

"See Mitchell and Deane (1962, pp. 401-409).

12Board of Governors of the Federal Reserve System (1943, p. 511). 
England [1995]): Canada has coupon bonds with maturities of around 30 years, Australia has coupon bonds with maturities of 20 years, and Israel has coupon bonds with maturities of 15 years. Sweden has discount bonds with maturities of 19 years - the duration of a consol would be 19 years if the real discount rate were about $5-1 / 2 \%$. The observed short maturity for public debt in modern times applies to nominal bonds in the context of a paper monetary standard. Nominal debt is considered below.

\section{Time Consistency of the Optimal Tax Policy}

The central issue in Lucas and Stokey (1983) is the design of a debt maturity structure to ensure time consistency of the optimal solution for tax rates. Their basic setup assumes no capital, a labor-leisure choice, and a proportional tax on labor earnings. Government purchases, $G_{t}$, are exogenous but random, and the model has no other sources of uncertainty. As Persson and Svensson (1984) note, the question of time consistency in the Lucas-Stokey model does not depend on randomness in the $G_{t}$ 's. Therefore, the issue can be addressed within a deterministic version of the model.

Persson and Svensson (1984) observe that time inconsistency in the Lucas-Stokey framework involves the linkage between the prospective path of labor tax rates and the equilibrium asset prices, $P_{t j}$, which appear in the government's budget constraint, an analog to equation (22) (modified for the form of the tax system). Heuristically, if a future $P_{t j}$ multiplies a positive term $\left(B_{t-1, j+1}-B_{t j}\right)$, then the government will have an incentive later to change policy so as to lower the particular $P_{t j}$ and thereby improve its budget situation. For a negative term, the opposite incentive applies. The way to avoid these incentives-that is, to achieve time consistency -is to adopt a plan in which all of the terms $\left(B_{t-1, j+1}-B_{t j}\right)$ are set to zero. As mentioned before, this condition was 
already assumed in the present context, not to ensure time consistency, but to avoid sensitivity of future tax rates to random variations in the prices of indexed bonds.

The more common source of time inconsistency in dynamic optimal tax problems, such as Chari, Christiano, and Kehoe (1994), is the potential for capital levies. ${ }^{13}$ This possibility does not arise in the Lucas-Stokey model because of the absence of "capital." The present model contains capital and therefore the potential for capital levies. Nevertheless, the proposed solution-a constant rate of consumption tax supported by the issue of indexed consols - is time consistent. The reason is that the overall level of taxation is not distorting in the model. Distortions arise, as can be seen from the firstorder condition in equation (20), only from prospective variations in the tax rate. If the consumption tax rate is stabilized-at whatever level-these timing distortions do not operate, and the economy attains the first-best (social planner's) equilibrium. For this reason, the benevolent government has no incentive to effect capital levies (or to default on its outstanding debt).

This conclusion is not robust to changes in the structure of the model; for example, the time-consistency problem would emerge if a labor-leisure choice or transaction costs for collecting taxes were introduced. In these cases, the overall level of tax rates would be distorting, and the benevolent government would have the usual incentive, ex post, to enact capital levies or to default on its debt. Households' expectations of these levies and defaults can preclude the optimal-tax solution as an equilibrium in a manner familiar from the rules-versus-discretion literature (initiated by Kydland and Prescott [1977]). The government would therefore have the usual incentive to create an institution or to maintain a reputation that inhibits capital levies and defaults. This is

${ }^{13}$ Chari, Christiano, and Kehoe (1994) "resolve" this problem by fixing the initial tax rate on capital arbitrarily. However, the optimizing government tends to choose a very high tax rate on capital in the second period. An alternative procedure, if full commitment is feasible, would be to assume that the rule for setting tax rates was known for dates going back to minus infinity. 
not to say that this institution/reputation problem has been solved in any kind of general manner. Rather, the point is that the problem cannot typically be eliminated by a clever design for the maturity structure of the debt (a point that is well recognized in Lucas and Stokey [1983]).

\section{Variations in Consumption and Government Purchases}

Return now to the optimal-tax solution, but assume that $C_{t}$ and $G_{t}$ can vary over time. In this case, the government may have an incentive to condition its debt payments on the realizations of the $C_{t}$ and $G_{t}$, as in Lucas and Stokey (1983) (with respect to variations in $G_{t}$ ). 14 If each of the $P_{t j}$ still exhibits independent random variation, then the terms $\left(B_{t-1, j+1}-B_{t j}\right)$ for $t>1$ in equation (22) again have to be set to zero to ensure perfect tax-rate smoothing. ${ }^{15}$ Hence, equation (23) becomes

$$
\begin{gathered}
\tau_{2}=\mathrm{g}_{2}+\mathrm{B}_{11} / \mathrm{C}_{2}, \\
\tau_{3}=\mathrm{g}_{3}+\mathrm{B}_{12} / \mathrm{C}_{3}, \ldots,
\end{gathered}
$$

${ }^{14}$ Contingent taxation of capital can be a substitute for contingent payments on debt, as shown in Judd (1991) and Chari, Christiano, and Kehoe (1994). A generous reading of Funding System, reprinted in McCulloch (1846, pp. 538, 540), would give Ricardo credit for this idea: "Suppose a country to be free from debt, and a war to take place which should involve it in an annual expenditure of 20 millions per annum-there are three modes by which this expenditure may be provided; first taxes may be raised to the amount of 20 millions per annum ... These large taxes, it may be said, must fall on property ..." [Hence, Ricardo had in mind a capital levy?] McCulloch (1846, p. xxviii) says in reaction: "He [Ricardo] was a decided friend to the plans for raising the supplies for a war within the year, by an equivalent increase of taxation; and he also thought (in which opinion few probably will be disposed to concur) that it would be not only expedient but practicable to pay off the public debt by an assessment on capital."

${ }^{15}$ The more general idea is that the government's budget constraint must be insensitive overall to the independent movements that occur in the prices of the government's obligations. 
where $g_{t} \equiv G_{t} / C_{t}$. In this case, equality of the $B_{1 j}$ for $j \geq 1$ would not generally be consistent with perfect tax-rate smoothing.

Suppose, for example, that $C_{t}$ and $G_{t}$ have a common upward trend, corresponding to the excess of the mean of the rate of return on capital, $r_{t k}$, over the rate of time preference, $\rho$, in equation (12). In this case, the $B_{1 j}$ have to exhibit the same trend to maintain a constant tax rate in equation (25). The next sections generalize this result to allow for random movements in $C_{t}$ and $G_{t}$.

1. Fluctuations in Aggregate Consumption Suppose, first, that the ratio $g_{t} \equiv G_{t} / C_{t}$ is a constant $g$, but that each of the $C_{t}$ exhibits independent random variation, perhaps relative to a positive trend. For example, in the model without taxation in equation (10), consumption reacts to disturbances to productivity and depreciation. Since $g_{t}$ is constant, equation (25) becomes

$$
\begin{gathered}
\tau_{2}=g+B_{11} / C_{2}, \\
\tau_{3}=g+B_{12} / C_{3}, \ldots
\end{gathered}
$$

Equation (26) implies that the stabilization of tax rates requires the payments on the government debt in each period to be state contingent; specifically, to pay an amount proportional to the period's level of aggregate consumption. The construction of these consumption-contingent claims raises some problems. First, consumption is difficult to define and measure. Second, the conditioning of the government's claims on aggregate consumption may influence the choice of its purchases, $G_{t}$ (which affects $C_{t}$ ), a possibility that is considered in the next section. These problems are ignored for now.

Redefine $B_{t j}$ so that each unit pays $C_{t+j} / C_{t}$ units of goods in period $t+j$, and let $P_{t j}$ be period $t$ 's price per unit of these claims. With this change in definition, 
equation (26) becomes

$$
\begin{gathered}
\tau_{2}=\mathrm{g}+\mathrm{B}_{11} / \mathrm{C}_{1}, \\
\tau_{3}=\mathrm{g}+\mathrm{B}_{12} / \mathrm{C}_{1}, \ldots
\end{gathered}
$$

Therefore, $B_{11}=B_{12}=\ldots$ (in the units defined as above) delivers $\tau_{t}=\tau_{t+1}$ for $t \geq 2$. The level of each debt payment, $B_{11}$, is determined by an expression analogous to equation (24).16

Thus, perfect smoothing of consumption tax rates requires the government to fund itself by means of indexed consols in which the indexation ensures real payoffs in relation to aggregate consumption. The desired form of security is similar to the GDPlinked bonds that have been proposed by Shiller (1993, Ch. 4). Presumably, Shiller bonds would have been called for if the government were stabilizing taxes in relation to GDP rather than in relation to consumption. Since GDP is easier than consumption to define and measure, GDP-linked bonds may be easier to implement in practice.

If debt payments cannot be conditioned on $\mathrm{C}_{\mathrm{t}}$, then the government may still be able to come close to the first-best solution in the present model. To see this, consider the government's optimal-tax problem as the search for a fiscal policy that makes the decentralized first-order condition in equation (20) coincide with (or come close to) the social planner's condition in equation (4).

Perfect tax-rate smoothing, $\tau_{t+1}=\tau_{t}$ for $t \geq 1$, achieves the first-best outcome, as already shown. But a weaker policy that also works admits tax-rate changes as long as

16In the revised expression, the right-hand side of the equation is the value of the period 0 debt evaluated at the prices applicable to this type of debt in period 1 (and $\mathrm{B}_{01}$ is the payout from the initial debt in period 1). In period 1 , the debt is restructured into the consumption contingent form described in the text. The government's policy is still feasible as long as $G_{t}=g C_{t}<Y_{t}$ applies in each period. 
they are unpredictable in a certain sense; namely the process for tax rates must take the form

$$
\frac{1}{1+\tau_{t+1}}=\frac{1}{1+\tau_{t}}+\epsilon_{t+1}
$$

where $E_{t}\left[\epsilon_{t+1}\left(1+A v_{t+1}-\delta_{t+1}\right) \cdot\left(C_{t+1}\right)^{-\theta}\right]=0$. Note that the term $\left(1+A v_{t+1}-\delta_{t+1}\right) \cdot\left(C_{t+1}\right)^{-\theta}$, which appears in the first-order condition in equation (20), is proportional to the product of $1+r_{t k}$ and the marginal utility of consumption. The key question is whether the tax-rate policy prescribed in equation (28), with the indicated properties for $\epsilon_{t+1}$, is consistent with the government's overall budget constraint. This constraint means that a bad shock-a low realization for $\mathrm{r}_{k t} \equiv A v_{t+1}-\delta_{t+1}$, which typically goes along with a low value for $\mathrm{C}_{\mathrm{t}}$-requires an increase in tax rates.

The term $\left(1+A v_{t+1}-\delta_{t+1}\right) \cdot\left(C_{t+1}\right)^{-\theta}$ is constant in the model without a government sector if utility is logarithmic $(\theta=1)$; see equation (10). That is, the effect from a high $\mathbf{r}_{t \mathrm{k}}$ is exactly offset by the resulting low marginal utility of consumption. The term is also constant with log utility in the social planner's model with a government sector if $g_{t}$ is constant.17 Since the proposed tax policy would, if feasible, generate the social planner's outcome, the condition $E_{t}\left[\epsilon_{t+1}\left(1+A v_{t+1}-\delta_{t+1}\right) \cdot\left(C_{t+1}\right)^{-\theta}\right]=0$ reduces here to $E_{t} \epsilon_{t+1}=0$. The problem is that this property is not generally obtainable if the debt payments cannot be conditioned on $\mathrm{C}_{\mathrm{t}}$.

${ }^{17}$ The solution for consumption can be shown in this case to be

$$
\mathrm{C}_{\mathrm{t}}=\frac{\rho}{(1+g) \cdot(1+\rho)} \cdot\left(1+\mathrm{A} \mathrm{v}_{\mathrm{t}}-\delta_{\mathrm{t}}\right) \cdot \mathrm{K}_{\mathrm{t}-1} \cdot
$$

This result reduces to equation (10) if $g=0$. 
Equation (26) implies that one feasible form of fiscal policy structures the debt in period 1 so that $B_{1, t-1}$ is proportional to the trend value of $C_{t}$. Then the fluctuations in $C_{t}$ show up as adjustments in the opposite direction in $\tau_{t}$ in order to satisfy equation (26). This policy seems to come close to supporting the first-best outcome if $\theta=1$; it does not work exactly because $E_{t} \epsilon_{t+1}$ is generally nonzero (although the debt maturity can be designed in period 1 so that $\mathrm{E}_{1} \epsilon_{\mathrm{t}+1}=0$ ). My conjecture is that the resulting distortion is third order. That is, the conditioning of debt payments on aggregate consumption is likely to be unimportant in the present model if utility is (nearly) logarithmic.

This result would not hold, however, if utility were far from logarithmic or with other forms of tax distortions. For example, Bohn (1990) and Judd (1991) assume that the distortion is a quadratic function of the realized tax rate in each period. In this case, the conditioning of debt payments on aggregate consumption or GDP would be more important.

2. Fluctuations in the Public Spending Ratio Suppose now that each of the $g_{t} \equiv G_{t} / C_{t}$ also exhibits independent random variation. Tax-rate stabilization in equation (25) then requires the debt payment in period $t$ to be contingent on the realization of $g_{t}$. Specifically, if the payment is already proportional to $C_{t}$, then the total payout for period $t$ must be reduced by the excess of $G_{t}$ over the amount of spending, $G_{1}{ }^{*}\left(C_{t} / C_{1}\right)$, that would be explained by consumption growth (for a fixed ratio $g_{t}$ ). The adjustment per unit of debt is larger in magnitude the smaller the aggregate quantity of debt outstanding. ${ }^{18}$

18Feasibility of the policy still depends on $G_{t}<Y_{t}$ in each period. 
The conditioning of debt payment on government spending raises two problems. First, if $G_{t}$ is treated (appropriately) as a choice variable of government, then the dependence of debt payments on public expenditure may motivate excessive spending, possibly even excessive wars. (The results depend on possibilities for committing the methods for choosing expenditures.) Because of this problem, Bohn (1990) assumes that payments on government debt cannot be conditioned on public outlays. Second, a realization of $G_{t}$ could be large enough to require a negative payout on debt; that is, the equity stake represented by a government bond could not generally be subject to limited liability. Negative payments-where the government requires payments from its bondholders-might arise during a large war and are more likely the smaller the initial aggregate quantity of public debt.

An inability to condition debt payments on $g_{t}$ means that a positive innovation to $g_{t}$ would tend to generate an increase in $\tau_{t}$ and a reduction in $C_{t}$. Thus, from the standpoint of equations (28) and (20), the innovations in the tax-rate expression, $\epsilon_{t+1}$ ' cannot be designed to be independent of the term in the first-order condition, $\left(1+A v_{t+1}-\delta_{t+1}\right) \cdot\left(C_{t+1}\right)^{-\theta}$, even under log utility. Distortions would arise (even with no labor-leisure choice) because tax rates would be high when the marginal utility of consumption was high.

\section{E. Nominal Debt}

Suppose now that the government can issue nominal bonds, where the riskless, one-period nominal rate of return in period $t$ is denoted by $R_{t 1}$. The real return depends on the realization of the corresponding inflation rate, $\pi_{t 1}$. Returns over longer horizons can be defined analogously. If the distribution for inflation over various horizons is specified, then it is possible to price these nominal assets within the model worked out before. 
Inflation depends on monetary policy, and the determination of this policy may interact with the fiscal considerations explored in this paper. For present purposes, however, the probability distribution for inflation is treated as exogenous. Moreover, the distortions created by inflation are assumed not to interact with those caused by other forms of taxes. (Bohn [1990] also takes this approach.)

The mean and variance of the inflation rate, $\pi_{t 1}$, may depend on lagged inflation and on lags of the variables already considered-the shocks that affect productivity, $v_{t}$ and $\delta_{t}$, the government spending ratio, $g_{\mathfrak{t}}$, and the level and structure of the public debt. Inflation may also co-vary with the contemporaneous values of $v_{t}, \delta_{t}$, and $g_{t}$.

The stochastic properties of inflation are assumed to reflect some empirical regularities. One of these regularities, applicable to the paper monetary standards of modern times, is that innovations to inflation are highly persistent. In fact, the inflation rate is close to being non-stationary in post-World War II data, say for the United States and the United Kingdom.

Another apparent regularity is that innovations to inflation tend to signal bad times ahead in the long run. As an indication of this pattern, for U.S. quarterly data from 1957 to 1994, the contemporaneous correlation of a measure of unexpected inflation with the real return on the stock market is negative and surprisingly large in magnitude, $-0.4 .^{19}$ In contrast, the short-term relation between the inflation rate and real GDP tends to be positive; that is, inflation is mildly procyclical. 20

${ }^{19}$ The series on expected inflation is an updated version of the one constructed in Barro (1992). These values come from an ARMA process with deterministic seasonals for CPI inflation, with the estimated coefficients updated each quarter to use only lagged data. The inflation rate is computed from monthly, seasonally unadjusted values of the CPI (or the CPI exclusive of shelter) for January, April, July, and October. Real stock returns are the growth rate of the S\&P 500 index less CPI inflation plus the S\&P 500 dividend yield. ${ }^{20}$ The departure of the price level from its trend tends, however, to be countercyclical. See Kydland and Prescott (1990) and Barro and Grilli (1994, pp. 14,15). 
An additional feature of inflation is its positive correlation with wartime spending, especially for such large conflicts as World Wars I and II and the Napoleonic Wars (see Barro [1987] for a discussion of the long-term British history). However, for the moderate fluctuations of government spending that show up in the U.S. data since World War II, there is no significant relation between innovations to inflation and movements in government expenditure.

Return to the theory and consider first the case in which $C_{t}$ and $G_{t}$ are constant. In this context, indexed consols provide for perfect tax-rate smoothing, even if riskless real rates of return vary randomly over time. Thus, the government's issue of nominal debt would obviously be a mistake in this setting. The resulting fluctuations in financing costs, due to unanticipated inflation, would create unnecessary variations in tax rates. The debt could be engineered to make most of the changes in tax rates unpredictable, but the fluctuations of inflation would have to generate some changes, ex post, in tax rates.

If indexed bonds are unavailable and the government is therefore forced to issue nominal bonds, then the maturity of the nominal debt could be designed to hold down the fluctuations in tax rates. Since innovations to inflation tend to persist, the prices of long-term nominal bonds would be more volatile that those of short-term bonds. Therefore, the greater the volatility of inflation the more the government would shift toward short-term issues to minimize the effect of unanticipated inflation on financing costs. For example, in the United States, the average maturity of the public debt (weighted by nominal amounts of principal outstanding) fell from around 9 years in 1946 to less than 3 years in 1976, then returned to about 6 years for 1989-94.21 The

21See Economic Report of the President, 1966, p. 275; 1995, p. 377. The definition of maturity often varies. For example, the standard measure could be improved by computing the effective duration, which weights the time to each coupon or principal payment by the present value of the amount outstanding. Errors arise for other countries in the treatment of floating-rate debt, which may have a long stated maturity but is 
drawback of this kind of shift to short-term issues is that the government's refunding costs become more sensitive to movements in real interest rates. (The reason for issuing indexed consols was to leave the government's budget constraint-and, hence, its tax rates-invariant with changes in riskless real interest rates.)

Bohn $(1988,1990)$ and Calvo and Guidotti (1990) argue that nominal debt may be a desirable form of funding because of the covariance of inflation with other variables, such as $G_{t}$ and $C_{t}$. Suppose first that $g_{t} \equiv G_{t} / C_{t}$ is constant. Then a tendency for inflation to be high in bad times means that the real returns on nominal government debt would tend to be low when $r_{k t}$ and $C_{t}$ were low. ${ }^{22}$ Thus, to some extent, nominal debt has the characteristic of the consumption-indexed bonds that have already been considered. The previous discussion suggested that this contingency would not be that valuable in the present model (because, with log utility, a low value of $1+r_{k t}$ goes along with an equiproportionately high value of the marginal utility of consumption). But, if this contingency were important, then it would be desirable to arrange it explicitly. The indirect route through nominal bonds is less effective because it introduces noise-and therefore tax-rate fluctuations-from random movements in inflation.

effectively short-term debt; see the discussion for Italy in Alesina, Prati, and Tabellini (1990, section 2). Missale and Blanchard (1994) define maturity in terms of the sensitivity of the market value of the debt to a change in the inflation rate. They therefore classify all indexed debt as zero maturity. Probably they should have found another term for their concept.

22This property means that nominal debt would have to pay an expected premium on indexed debt, as found for medium and long-term bonds in the U.K. data; see Breedon (1995) and Bank of England (1995). The idea that indexed bonds would provide relatively cheap financing was mentioned by Tobin (1971, p. 416): "The introduction of such bonds [indexed bonds] might be economical to the Treasury because the general public would be willing to accept lower yields in order to avoid the risks of changes in the price level." Because of the persistence of shocks to inflation, the negative effect of bad events on real returns tends to be larger in magnitude for longer term nominal bonds. Therefore, the nominal term structure would usually be upward sloping. At the very short end, the procyclical behavior of inflation may cause the expected real return on nominal debt (say 3 -month treasury bills) to be lower than that on the corresponding indexed debt. 
The previous discussion suggested that a dependence of debt payments on the government's spending ratio, $g_{t}$, would be desirable, except for the moral-hazard problems that would be created. Given the observed behavior of inflation-that it relates to government spending mainly during major wars-the issue of nominal bonds would create a significant dependence of real debt payments on government spending primarily during these wars. In other words, the principal benefit from nominal debt issue is that it allows for partial default via inflation during wartime.

It is clear that tax-rate smoothing can be facilitated by issuing debt that pays off poorly when government spending is high. It is also clear that this conditionality may create a moral-hazard problem in the determination of spending levels, although this problem may be minor if the conditioning applies only to "clear-cut emergencies," such as large wars. ${ }^{23}$ In any event, it is hard to see why the tradeoff between desirable contingencies and moral hazard works out better with nominal debt than with bonds that are conditioned explicitly on government spending or other indicators of the state of emergency. Nominal debt seems always to be inferior in that it involves the same moral hazard but also introduces a good deal of unnecessary randomness. Thus, overall, nominal debt seems to be a bad idea.

\section{Final Thoughts}

My usual approach to analyzing government behavior is to seek explanations that do not rely on systematic errors by policymakers. Thus, if the model predicts that certain types of funding are more efficient than others, then the model receives empirical support if the actual practices of governments conform in some respects to the model's prescriptions. An example is the tendency for indexed government bonds to have much

23If the contingency is viewed as a prize for the government in proportion to the number of military casualties that it creates, then the moral-hazard problem sounds more serious. 
longer maturities than conventional (nominal) government bonds, especially in papermoney systems with volatile inflation.

Nevertheless, at the risk of saying something normative, it seems that the widespread reliance of governments on nominal debt has been a mistake. This judgment is perhaps more convincing if one accepts the idea that this form of security is a relatively recent invention. Most government bonds have effectively been nominal only under the paper money standards that became widespread during the twentieth century, especially with the movement away from gold during World War I and the collapse of the Bretton Woods standard in the early 1970 s.

Policies in the main developed countries have been changing in two ways to counter the paramount position of nominal debt as a method of government funding. First, the use of indexed bonds has been increasing, notably in countries that have not been subject (recently) to high and volatile inflation. The United Kingdom has taken the leading position since 1982, but other recent issues of indexed debt by governments have occurred in Australia, Canada, Iceland, and Sweden, and will appear soon in New Zealand. Such issues are also being actively considered in the United States.

Second, paper-money standards with high and volatile inflation have themselves been transformed. The movement toward more independent central banks with commitments to price stability represents a shift toward monetary systems in which the value of money is more reliable. In these arrangements, nominal debt is more like real debt, and the choice between indexed and conventional bonds becomes less important.

From a normative standpoint, a key result is the recommendation for public debt to be indexed to the price level and long term. This structure is desirable because it insulates future government budget constraints -and, hence, future tax rates-from changes in real interest rates. 
Nominal debt is intrinsically inferior because it allows random fluctuations in inflation to influence the government's future budget constraints and, hence, tax rates. These departures from tax-rate smoothing impose unnecessary distortions on the economy.

A full program of optimal taxation also calls for debt payments to be contingent on the tax base (aggregate consumption in the main model of this paper) and the level of government spending. However, other considerations-notably moral-hazard problems associated with the determination of public outlays - may make these contingencies unattractive. In this case, perfect tax-rate smoothing is unattainable, because tax rates have to respond to unanticipated changes in the tax base and the level of government spending. Even in this case, however, long-term indexed debt seems to be the preferred form of public finance, and nominal bonds are still a bad idea. 
References

Abel, A.B., N.G. Mankiw, L.H. Summers, and R.J. Zeckhauser (1989). "Assessing Dynamic Efficiency: Theory and Evidence," Review of Economic Studies, 56 (January), 1-20.

Alesina, A., A. Prati, and G. Tabellini (1990). "Public Confidence and Debt Management: a Model and a Case Study of Italy," in R. Dornbusch and $M$. Draghi, eds., Public Debt Management: Theory and History, Cambridge, Cambridge University Press.

Bank of England (1995). "The U.K. Index-Linked Gilt-Edged Market: Future Development," overview papers for the conference of 14/15 September 1995.

Barro, R.J. (1979). "On the Determination of the Public Debt," Journal of Political Economy, 87 (October), 940-971.

Barro, R.J. (1987). "Government Spending, Interest Rates, Prices, and Budget Deficits in the United Kingdom, 1730-1918," Journal of Monetary Economics, 20 (September), 221-247.

Barro, R.J. (1992). "World Interest Rates and Investment," Scandinavian Journal of Economics, 94 (2), 323-342.

Barro, R.J. and V. Grilli (1994). European Macroeconomics, London, Macmillan.

Barro, R.J. and X. Sala-i-Martin (1995). Economic Growth, New York, McGraw-Hill.

Board of Governors of the Federal Reserve System (1943). Banking and Monetary Statistics, Washington D.C., National Capital Press.

Bohn, H. (1988). "Why Do We Have Nominal Government Debt?," Journal of Monetary Economics, 21 (January), 127-140.

Bohn, H. (1990). "Tax Smoothing with Financial Instruments," American Economic Review, 80 (December), 1217-1230. 
Breeden, D.T. (1979). "An Intertemporal Asset Pricing Model with Stochastic Consumption and Investment Opportunities," Journal of Financial Economics, 7, 265-296.

Breedon, F. (1995). "Bond Prices and Market Expectations of Inflation," Bank of England Quarterly Bulletin, 35 (May), 160-165.

Calvo, G. and P. Guidotti (1990). "Indexation and Maturity of Government Bonds: an Exploratory Model," in R. Dornbusch and M. Draghi, eds., Public Debt Management: Theory and History, Cambridge, Cambridge University Press. Campbell, J.Y. (1995). "Consumption and the Stock Market: Interpreting International Evidence," unpublished paper, Harvard University, September. Campbell, J.Y. and J.H. Cochrane (1994). "By Force of Habit: A Consumption-Based Explanation of Aggregate Stock Market Behavior," unpublished paper, Harvard University, September.

Chamley, C. (1986). "Optimal Taxation of Capital Income in General Equilibrium with Infinite Lives," Econometrica, 54 (May), 607-622.

Chari, V.V., L.J. Christiano, and P.J. Kehoe (1994). "Optimal Fiscal Policy in a Business Cycle Model," Journal of Political Economy, 102 (August), 617-652.

Friedman, M. (1959). A Program for Monetary Stability, New York, Fordham University Press.

Giavazzi, F. and M. Pagano (1990). "Confidence Crises and Public Debt Management," in R. Dornbusch and M. Draghi, eds., Public Debt Management: Theory and History, Cambridge, Cambridge University Press.

Grossman, S. and R. Shiller (1982). "Consumption Correlatedness and Risk Measurement in Economies with Non-Traded Assets and Heterogeneous Information," Journal of Financial Economics, 10, 195-210. 
Judd, K.L. (1985). "Redistributive Taxation in a Simple Perfect-Foresight Model," Journal of Public Economics, 28 (October), 59-83.

Judd, K.L. (1991). "Optimal Taxation in Dynamic Stochastic Economies: Theory and Evidence," unpublished paper, Hoover Institution, January.

Kydland, F.E. and E.C. Prescott (1977). "Rules Rather than Discretion: the Inconsistency of Optimal Plans," Journal of Political Economy, 85 (June), $473-491$.

Kydland, F.E. and E.C. Prescott (1990). "Business Cycles: Real Facts and a Monetary Myth," Federal Reserve Bank of Minneapolis, Quarterly Review, Spring, 3-18.

Lucas, R.E. and N.L. Stokey (1983). "Optimal Fiscal and Monetary Policy in an Economy without Capital," Journal of Monetary Economics, 12 (July), 55-93.

Mankiw, N.G. and S.P. Zeldes (1991). "The Consumption of Stockholders and Nonstockholders," Journal of Financial Economics, 29, 97-112.

McCulloch, J.R. (1846). The Works of David Ricardo, London, John Murray. Missale, A. and O.J. Blanchard (1994). "The Debt Burden and Debt Maturity," American Economic Review, 84 (March), 309-319.

Mitchell, B.R. and P. Deane (1962). Abstract of British Historical Statistics, Cambridge, Cambridge University Press.

Persson, T. and L.E.O. Svensson (1984). "Time-Consistent Fiscal Policy and Government Cash-Flow," Journal of Monetary Economics, 14 (November), $365-374$.

Pigou, A.C. (1928). A Study in Public Finance, London, Macmillan.

Shiller, R.J. (1993). Macro Markets, Creating Institutions for Managing Society's Largest Economic Risks, Oxford, Clarendon Press.

Stokey, N.L. and R.E. Lucas, with E.C. Prescott (1989). Recursive Methods in Economic Dynamics, Cambridge MA, Harvard University Press. 
Tobin, J. (1971). "An Essay on the Principles of Debt Management," in J. Tobin, Essays in Economics, Volume 1, Macroeconomics, Chicago, Markham Publishing Company. 